\title{
A HAZARD ASSOCIATED WITH IMPROPER CONNECTION OF THE BAIN BREATHING CIRCUIT
}

\author{
J.G. Paterson and V. Vanhooydonk
}

THE STREAMLINED MODification of the Mapleson D circuit, described by Bain and Spoerel, ${ }^{1}$ is used almost exclusively in the hospitals in London, Ontario. This circuit relies for proper function on the introduction of fresh gases very close to the patient's airway. Improper connection of the breathing circuit can convert the entire length of the breathing tube into added deadspace, resulting in hypercarbia and hypoxia, representing a serious hazard to the patient. The following case report demonstrates the possibility of connecting the circuit the wrong way; in addition the effect of such a faulty connection was investigated further in a dog.

\section{Case History}

A 13-year-old girl complaining of right shoulder pain after a fall was admitted through the emergency department and diagnosed as a Salter Type II fracture. The girl weighed 43 kilograms and was otherwise in good health, having no known allergies.

For the surgical repair the patient was anaesthetized with thiopentone and given succinylcholine $(1 \mathrm{mg} / \mathrm{kg})$ for tracheal intubation. Anaesthesia was maintained with nitrous oxide and oxygen, with flow rates of 5 and 2 litres respectively and 0.5 to 1 per cent halothane. Succinylcholine drip $(1 \mathrm{mg} / \mathrm{cc}$ ) was used to provide muscular relaxation with manually controlled ventilation. Heart sounds were continuously monitored with a precordial stethoscope.

About 90 minutes after the induction of anaesthesia, a marked bradycardia was noted associated with hypotension. All anaesthetic agents were discontinued and the patient ventilated with oxygen. Shortly thereafter the heart sounds disappeared and external chest compression was begun immediately resulting in a quick return of good pulse and acceptable blood pressure. An arterial sample was taken at this time (Table I). When the result of the blood gas determination revealed a marked elevation of the arterial $\mathrm{CO}_{2}$ tension $(123 \mathrm{~mm} \mathrm{Hg}$ ) a second sample was drawn to confirm this result. It was felt that the hypercarbia could be caused by a disconnected inner tube as described by Hannallah and Rosales, ${ }^{2}$ although the inner tube could be seen in proper position through the translucent outer tube. However, the breathing tube (which was subsequently found in good condition) was changed. During the change it was noted that the fresh gas inflow line had been connected by mistake to the nipple for the pressure manometer of the respirator, while the manometer was connected to the inflow orifice of the Bain tube as shown in Figure

-Department of Anaesthesia, University of Western Ontario and Victoria Hospital, London, Ontario. 
TABLE I

The Blood Gas Results of a Patient who Suffered a Circulatory Arrest Due to an Incorrectly Connected Bain Tube

\begin{tabular}{cccccc}
\hline \hline $\mathrm{O}_{2}$ & Time $(\mathrm{min})$ & $\mathrm{Pa}_{\mathrm{O} 2}$ & $\mathrm{pH}$ & $\mathrm{Pa}_{\mathrm{CO}_{2}}$ & B.E. \\
\hline $100 \%$ & 0 & 211 & 6.95 & 123 & -7 \\
$100 \%$ & 20 & 303 & 6.85 & 150 & -6 \\
& 30 (tube connected properly) & 7.29 & & 49 & -3 \\
$100 \%$ & 75 & 303 & 7.33 & 41 & -4 \\
$30 \%$ & 195 & 125 & 73 \\
\hline
\end{tabular}

FIGURE 1A, CORRECT

\section{FIGURE IA}

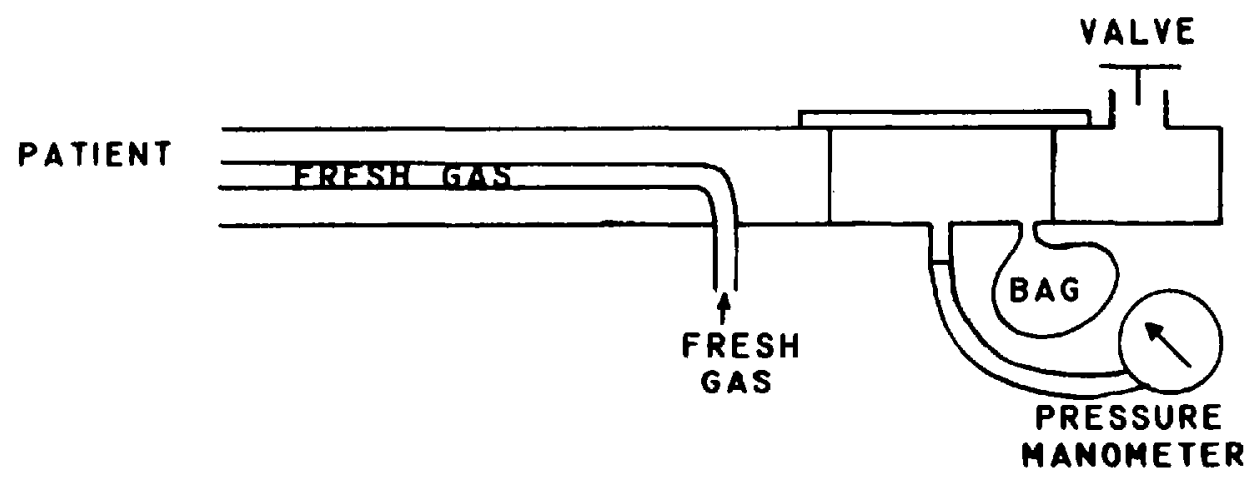

FIGURE 1B, INCORRECT

FIGURE IB

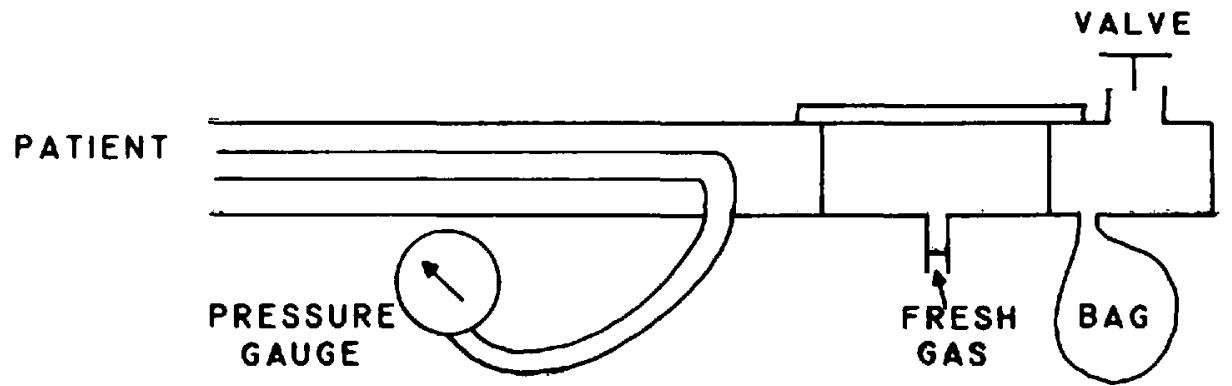

The whole tube now becomes dead space and the fresh gas escapes through the valve, building up $\mathrm{CO}_{2}$ in the patient.

Figure 1. The correct and incorrect method of connecting a Bain tube to a gas machine. 
PATERSON \& VANHOOYDONK: IMPROPER CONNECTION OF BAIN BREATHING CIRCUIT

TABLE II

The Blood Gas Results of a Dog that was Given General Anaesthesia with a Bain Tube CONNECTED INCORRECTLY

\begin{tabular}{lcccccc}
\hline \hline $\mathrm{O}_{2}$ & Time (Min) & $\mathrm{pH}$ & $\mathrm{PO}_{2}$ & $\mathrm{PCO}_{2}$ & $\mathrm{HCO}_{2}$ & B.E. \\
\hline $30 \%$ & 0 & 7.31 & 96 & 44 & 21 & -4 \\
& 15 & 7.16 & 62 & 59 & 18 & -8 \\
& 30 & 7.15 & 69 & 58 & 17 & -8 \\
45 & 7.12 & 40 & 65 & 17 & -9 \\
& 60 & 7.05 & 43 & 80 & 16 & -11 \\
& 75 & 7.00 & 41 & 85 & 15 & -13 \\
& 90 & 6.90 & 30 & 100 & 12 & -17 \\
& 105 (arrest) & 6.81 & 17 & 110 & 12 & -20
\end{tabular}

1B. Two further blood gas samples taken after the breathing tube was properly connected (Figure 1A) showed a return of her values to normal (Table I). At the end of the operation, approximately one hour after the brief cardiac arrest, the patient appeared to recover normally and was extubated on return of the protective reflexes of the airway. Her subsequent recovery was uneventful and she left the Recovery Room three hours later fully conscious and well oriented.

\section{LABORATORY INVESTIGATION}

An attempt was made to reproduce these sequence of events in a dog with the incorrectly connected circuit as shown in Figure 1B.

A male dog weighing 17.5 kilograms was induced with sodium thiopentone and the trachea was intubated. A succinylcholine drip was then started and the ventilation was controlled. A Bain breathing circuit was shortened from its normal length of $180 \mathrm{~cm}$ to $73 \mathrm{~cm}$ in order to obtain the same ratio between body weight and external deadspace as existed in the patient. The fresh gas inflow rate was also reduced proportionally to a flow of nitrous oxide 2 litres, oxygen 0.8 litres. Samples for arterial blood gas determinations were taken at 15-minute intervals and the results are shown in Table II.

Blood gas results showed a progressive rise in $\mathrm{Paco}_{2}$ with a concomitant decline in oxygen tension. About one hour and forty-five minutes after the start of ventilation, the dog developed a marked bradycardia followed by a cardiac arrest. Attempts to resuscitate the heart failed.

\section{Discussion}

In the Bain breathing circuit the fresh gas flow is delivered close to the connection with the tracheal tube, with an external deadspace of approximately 4 cc. However, with the circuit connected improperly as it is shown in Figure 1B, the entire volume of the tube between the tracheal tube and the point of entry of fresh gas would become external deadspace ( $584 \mathrm{ccs}$ ). The fixed volume of ventilation delivered by the respirator and the fixed fresh gas inflow permit no compensation for this large added deadspace and this will result in a marked accumulation of carbon dioxide. While this mistake might have been discovered early in a patient 
breathing spontaneously, it is virtually impossible to detect hypercarbia in the paralyzed patient on controlled ventilation.

As shown in the animal experiment (Table II) the rise in carbon dioxide is accompanied by a concomitant fall in oxygen tension and the bradycardia presenting the first significant sign of the impending disaster is likely due to the effect of hypoxia superimposed on a state of marked respiratory acidosis. In the patient, pure oxygen had been administered just prior to the blood gas determination, obscuring the existing hypoxia at the time of arrest. The rapid recovery of the patient's circulation indicates that acute severe respiratory acidosis is quite well tolerated for short periods of time as long as normal $\mathrm{P}_{\mathbf{O}_{2},}$ can be maintained.

Constant vigilance is required to prevent accidents of this type, particularly in a busy practice and where the anaesthetist is not setting up his own anaesthetic machine. Obviously it is essential that the anaesthetist using this breathing circuit is familiar with its function and is aware of the possibility of connecting this equipment the wrong way and the complications resulting from this. In order to avoid a repetition of this error the line to the pressure manometer of the Air Shields ventimeter ventilator has been fused in all ventilators to the $T$-piece connection that fits into the breathing circuit and we recommend this safeguard to other anaesthetists using the Bain circuit together with the Air Shields ventimeter ventilator.

\section{Summary}

A case of cardiac arrest is presented which was caused by improper connection of a modified Mapleson D circuit (Bain breathing circuit). Excessive external deadspace was created by interchanging the gas inflow line and the attachment for an airway pressure manometer. This resulted in a marked respiratory acidosis, clinically undetected until the concomitant hypoxia produced a severe cardiac depression and arrest. The sequence of events was reproduced in a dog under comparable anaesthetic conditions.

In order to avoid this error it is recommended to permanently fuse the connecting piece placed in the circuit with the tubing leading to the airway pressure manometer of the respirator.

\section{RésumÉ}

L'article rapporte un arrèt cardiaque occasionné par une erreur de montage, d'un système de Bain: le tube d'amenée des gaz frais a été branché par mégarde sur la prise destinée à la mesure de la pression des voies aériennes; ceci équivalait à ajouter un espace mort de $584 \mathrm{ml}$. L'acidose respiratoire marquée qui s'en suivit est demeurée masquée jusqu'a l'apparition d'hypoxie qui elle a causé une dépression aiguë du myocarde menant jusqu'à l'arrêt circulatoire.

Cette séquence a été exactement reproduite chez un chien soumis à des conditions anesthésiques identiques.

Pour prévenir toute répétition de cette erreur, il est recommandé de fixer de façon permanente, au système Bain, le tube reliant celui-ci au manomètre de pression du respirateur. 
PATERSON \& VANHOOYDONK: IMPROPER CONNECTION OF BAIN BREATHING CIRCUIT 377

\section{ACKNOWLEDGMENTS}

The authors would like to thank Miss Janet Ritchie, who typed the manuscript, Dr. Gordon Sellery, Chief of Anaesthesia, Victoria Hospital and Dr. Wolfgang Spoerel, Professor of Anaesthesia, University of Western Ontario for their advice on the manuscript.

\section{REFERENCES}

1. Bain, J.A. \& Spoerel, W.E. A streamlined anaesthetic system. Can. Anaes. Soc. J. 19: $426(1972)$

2. Hannallah, R. \& Rosales, J.K. A hazard connected with re-use of the Bain's Circuit: a case report. Can. Anaes. Soc. J. $21: 5$ (1974). 